\title{
DEVELOPMENT OF VARIABILITY CONCEPT IN ACCOUNTING: UKRAINIAN CONTEXT
}

\author{
Serhii Lehenchuk ${ }^{1}$ \\ Zhytomyr State Technological University, Ukraine \\ Yurii Velykyi ${ }^{2}$, Svitlana Belinska ${ }^{3}$ \\ Petro Mohyla Black Sea State University, Ukraine
}

\begin{abstract}
The purpose of the article is to develop theoretical fundamentals of the concept of variability in accounting taking into account development features of NAS under the influence of trends of accounting harmonization and standardization. The need to regulate the accounting system arose due to the current imperfection of financial markets and incomplete information about the activities of enterprises, which is provided to participants in such markets for decision-making. Accounting is a means to eliminate various negative phenomena that accompany the functioning of financial markets (incomplete information, information noise, information asymmetry). In order to improve the efficiency of accounting as a separate socio-economic institute that solves market imperfections, there is a need for its regulation based on the application of different kinds and types of models. One of the obligatory conditions for an efficient market operation is the availability of an ideal and complete market for accounting information, when all actors know the real financial situation and the results of each enterprise's financial statements, have an equal access to market information that may be used both for making economic decisions, and for carrying out accounting choice. Methodology. The theoretical and methodological basis of the paper is a complex and systematic approach in the study of the development of the variance concept in accounting. The methodology of accounting is an important tool for regulating the economy at all levels. The modern methodological situation in the Ukrainian economy is characterized by the transition from a unified, government-controlled methodology to a variety of methodological foundations. The absence of research on issues of improving the methodology of accounting did not allow providing the appropriate methodological orientation to measures for regulation and development of accounting in Ukraine. In this regard, the article studies the development of the concept of variability in accounting. Results. The following types of variability in accounting are highlighted: complete univariability; extended univariability; limited multivariability; partially limited multivariability; full unlimited multivariability. The structural model of the accounting system, based on the concept of limited multivariability, is proposed. Practical implications. Development features of the accounting system in countries with the developed market economy and post-Soviet countries are substantiated. A hierarchical structure of the accounting methodology is developed. In order to form theoretical aspects of the concept of the methodology of variability in accounting, its main concepts (imperative behaviour, accounting choice) are substantiated. Value/originality. Considered issues of the relationship of accounting choice with the concept of variability in the light of the positive theory of accounting revolutionize the views of researchers-accountants on the issue of accounting choice. In particular, this also applies to representatives of the domestic scientific community, which consider the accounting choice in the context of the concept of accounting policy of the enterprise. On the other hand, the positive theory of accounting proposes its way of the influence of the scientific community on developers of accounting standards. The methodology for explaining the reasons for making accounting choices by managers and foreseeing the actions of users of accounting information in the market, which, in turn, is a reaction to the disclosure of financial statements and the actions of managers, is a sufficient ground for understanding the implications of accounting decisions.
\end{abstract}

Key words: accounting system, accounting imperatives, accounting alternatives, variability, concepts, accounting policy.

JEL Classification: L84, M40, 012

\footnotetext{
Corresponding author:

${ }^{1}$ Department of Accounting and Audit, Zhytomyr State Technological University.

E-mail: legenchyk2014@gmail.com

${ }^{2}$ Department of Accounting and Audit, Petro Mohyla Black Sea State University.

E-mail: melek2405@bigmir.net

${ }^{3}$ Department of Accounting and Audit, Petro Mohyla Black Sea State University.

E-mail: melek2405@bigmir.net
} 


\section{Introduction}

The need to regulate the accounting system arose as a result of the current imperfection of financial markets and incomplete information about the activities of enterprises, which is provided to their participants for decision-making. Accounting is a means to eliminate various negative phenomena that accompany the functioningoffinancialmarkets (incompleteinformation, information noise, information asymmetry). In order to improve the efficiency of accounting as a separate socioeconomic institute that solves market imperfections, there is a need for its regulation based on the application of different kinds and types of models. The introduction of a multivariate accounting model in IAS/IFRS and GAAP US systems, although it is a significant step forward in improving the efficiency of their regulation, in itself this process does not eliminate all the disadvantages inherent in accounting systems built on the basis of a consistent accounting methodology. One of the ways to solve such problems is to develop a concept of variability in accounting, which allows the formation of further directions for the development of the regulation of the national accounting system (hereinafter - NAS), taking into account the advantages and disadvantages of various forms of methodological variability and accounting choice, which the agents of accounting organization in the enterprise have the right to make. The issue of multivariability in accounting in the context of the application of enterprises' accounting policy was given attention by the following domestic scientists: T.V. Baranovska, M.I. Bondar, B.I. Valuiev, S.F. Holov, V.V. Yevdokymov, P.Ye. Zhytnyi, V.M. Zhuk, R.V.Kostyrko, R.V.Kuzina, N.O.Lokhanova,A.V.Ozeran, O.M. Petruk, I.V. Suprunova, L.V. Chyzhevska.

\section{Analysis of the historical development of accounting}

Each NAS can be considered in the light of the concept of the variability of accounting methodology, which allows analysing it at an angle of availability/ absence of accounting choices in the process of accounting in the enterprise. An analysis of the historical development of accounting in the Tsarist Russia, the USSR, Ukraine, and the USA (until 1934 and after), the peculiarities of the development of the system of IFRS allowed to identify that there are different types of concepts of variability, on the basis of which NAS can be constructed (Table 1). The basic concepts that are used in any of the variants of the concept of variability in accounting are imperatives, alternatives, imperative behaviour, and accounting choice, the relationship between which is presented in Figure 1.

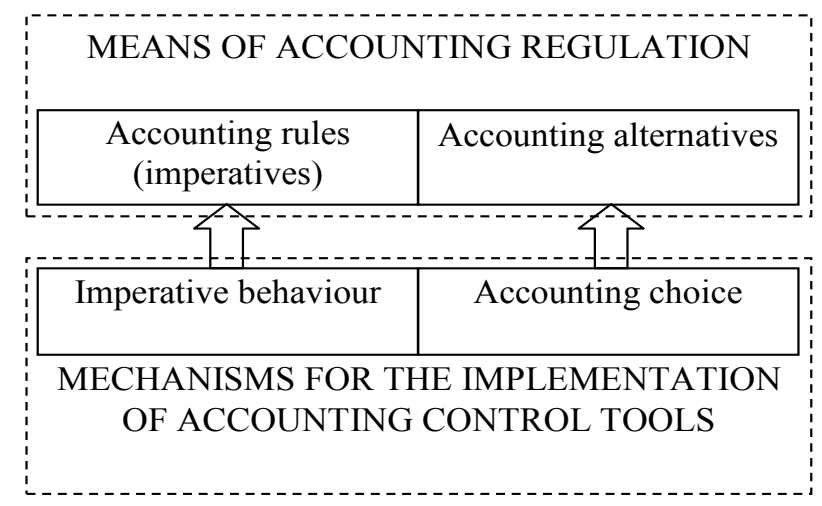

Figure 1. The interconnection between the basic concepts of the concept of variability in accounting

Table 1

Types and characteristics of variability concepts in accounting

\begin{tabular}{|c|c|c|c|c|c|}
\hline Concept type & $\begin{array}{c}\text { Complete } \\
\text { univariability } \\
\text { (only imperatives) }\end{array}$ & $\begin{array}{l}\text { Extended univariability } \\
\text { (imperatives, sometimes } \\
\text { alternatives, from which the } \\
\text { relevant authorities of a higher } \\
\text { level than the enterprise } \\
\text { choose) }\end{array}$ & $\begin{array}{c}\text { Limited } \\
\text { multivariability } \\
\text { (imperatives and } \\
\text { limited alternatives } \\
\text { (by qualitative } \\
\text { characteristics or } \\
\text { principles)) }\end{array}$ & $\begin{array}{c}\text { Partially limited } \\
\text { multivariability } \\
\text { (only alternatives } \\
\text { limited by } \\
\text { principles) }\end{array}$ & $\begin{array}{c}\text { Full unlimited } \\
\text { multivariability } \\
\text { (only alternatives) }\end{array}$ \\
\hline Concept formula & $\mathrm{I}$ & $\mathrm{I}, \mathrm{A}_{\mathrm{opr}}$ & $\mathrm{I}, \mathrm{OA}$ & $\mathrm{OA}$ & A \\
\hline $\begin{array}{l}\text { A form of } \\
\text { implementation } \\
\text { of the concept at } \\
\text { the level of the } \\
\text { accounting system }\end{array}$ & $\begin{array}{l}\text { Regulations, } \\
\text { guidelines for } \\
\text { accounting }\end{array}$ & $\begin{array}{l}\text { Regulations, guidelines for } \\
\text { accounting, the accounting } \\
\text { policy of bodies higher in } \\
\text { relation to the enterprise }\end{array}$ & $\begin{array}{c}\text { Accounting } \\
\text { standards, accounting } \\
\text { policy of the } \\
\text { enterprise }\end{array}$ & $\begin{array}{l}\text { Accounting policy } \\
\text { of the enterprise }\end{array}$ & $\begin{array}{l}\text { Accounting policy of } \\
\text { the enterprise }\end{array}$ \\
\hline \multirow[t]{2}{*}{$\begin{array}{c}\text { An example } \\
\text { of a concept } \\
\text { implementation }\end{array}$} & \multirow[t]{2}{*}{-} & \multirow[t]{2}{*}{$\begin{array}{l}\text { The accounting system in the } \\
\text { USSR after the 1930s. }\end{array}$} & \multirow[t]{2}{*}{$\begin{array}{l}\text { National P(S)A, } \\
\text { IAS/IFRS, GAAP } \\
\text { UK, GAAP US }\end{array}$} & $\begin{array}{l}\text { L. Pacioli's system } \\
\text { of accounting }\end{array}$ & $\begin{array}{c}\text { The accounting } \\
\text { system that existed } \\
\text { before the emergence } \\
\text { of principles }\end{array}$ \\
\hline & & & & $\begin{array}{c}\text { NAS in the USA } \\
\text { until } 1934\end{array}$ & $\begin{array}{l}\text { "Theory of multi- } \\
\text { purpose accounting" }\end{array}$ \\
\hline
\end{tabular}

Notes: I - imperatives; $\mathrm{A}$ - alternatives; $\mathrm{A}_{\mathrm{opr}}$ - alternatives, from which the relevant body of higher level than the enterprise chooses; $\mathrm{OA}$ - alternatives, the process of selection among which has certain restrictions. 
Accounting rules (imperatives) are such means of its regulation, which clearly and unambiguously establish an exhaustive list of the accounting reflection of consequences of business operation items of the enterprise and do not allow any deviations. The implementation of actions clearly defined in the accounting regulation documents by the accounting entity is called imperative behaviour. Accounting alternatives are a set of (two or more) equivalent accounting imperatives, the availability of which implies that for the accounting reflection of consequences of business operation items, it is necessary to choose one of them. The choice by the subject of accounting of one of the alternatives presented is called the accounting choice.

\section{The essence of each type of variability concept}

The concept of complete univariability suggests that accounting is governed by regulatory documents, in which there are no alternative options for accounting. The accountant must strictly observe the requirements stated in the documents (regulations, instructions) of the imperatives during the accounting reflection of the consequences of business operation items. We cannot give examples of the application of this concept today, but its allocation has important economic value, similar to Robinson Crusoe's economic model, which allows representing the economy of one agent. So the concept of complete univariability allows theoretically considering the existence of an accounting system, in which there are only imperatives and there is no possibility of an accounting choice both at the enterprise level and at the level of bodies of higher than the enterprise level.

The concept of extended univariability envisages that in the vast majority of cases, accounting is governed by the establishment of clear rules of conduct, but in some cases, the relevant documents provide for alternative versions of the accounting reflection of business operation items. The choice of alternatives presented in the documents is carried out by the appropriate authorities of higher than the enterprise level. The right to make a choice from the submitted alternatives entrusted to the subject of accounting. A typical example of this concept's practical implementation is the system of accounting in the USSR after the 1930s and before its collapse, the basis of which was built on the need to ensure the uniformity of accounting indicators to the indicators of the plan, which led to the elimination of most accounting alternatives used in the Soviet accounting methodology during the NEP.

Today, for example, the construction of a model of accounting regulation based on the concept of extended univariability, according to C. Sottoriva et al. (Sottoriva, 2013) is the development of a system of Iranian rulebased accounting standards based on the instructions and take into account the specific conditions of the political and economic structure of Iran.

The concept of limited multivariability is based on a mixed approach to NAS regulation, which involves the simultaneous application of accounting imperatives and a set of alternatives to the accounting of the consequences of business operation items. In comparison with two previous concepts, it provides a greater flexibility for subjects when choosing accounting methods. The form of implementation of the concept at the level of accounting system is often the accounting standards. The right to choose alternatives presented in standards is entrusted to the entity of accounting or management of the enterprise. When making accounting choices, a set of restrictions (principles or qualitative characteristics of accounting (financial) information) must be taken into account, which is recorded in the reference document of accounting standards (law or conceptual basis). To date, the concept of limited multivariability is realized in the vast majority of national and international accounting systems.

The concept of partially unlimited multivariability implies that accounting is governed only by the use of sets of alternative variants of accounting for the consequences of business operation items. When an accounting entity conducts accounting choice, which involves the choice of one appropriate alternative from each set, limitations in the form of accounting principles are taken into account. An example of implementing this concept in practice is the accounting system described by L. Pacioli or the accounting system in the USA, which existed before its reform in 1934 as a result of aggravation of crisis phenomena in the field of corporate governance and economics, one of the reasons for which was the imperfect regulation of the accounting system.

The concept of full unlimited multivariability assumes that accounting is regulated only through the use of sets of alternative variants of accounting reflection of the consequences of business operation items, in the choice of which there are no restrictions. That is, accounting choice by accounting subjects is carried out without taking into account any formal (normative) and informal (historically formed principles or postulates of accounting) recommendations. An example of the implementation of such a concept is the accounting systems that existed prior to the emergence of principles or postulates in them or do not foresee the need for their allocation.

Each enterprise has its micro and macro external environment, which, even at the level of theoretical developments, are not yet fully included in the objects of accounting monitoring. As enterprises are different, they also have different external environments, which is explained by the impact of different economic realities on their operation. The existence of these differences leads to the use of accounting entities different methods of accounting for the same objects. 
In addition, the information needs of internal and external users in relation to the same objects of accounting can vary considerably, which also affects the choice of different accounting methods. Thus, for all enterprises, it is rather difficult to choose the only best method. It is also impossible to do even for a particular type of operations, not to mention all the objects of accounting monitoring. At each enterprise, the entity that implements accounting policies chooses those accounting methods that are most useful for decisionmaking by users of accounting information and in most relevant and adequate manner reflect the information about the enterprise and the external environment, in which it operates.

Professor D. Solomons highlights four arguments against the complete freedom to choose accounting methods:

- the market cannot be dependent on the decisions of corporations regarding how and what they should report;

- the need to ensure the comparability of information disclosed by enterprises;

- the user of the accounting information must have the ability to understand and use it;

- increasing public confidence in financial reporting (Solomons, 1983).

The above arguments convincingly indicate the need to move from the concept of partially unlimited variability to the concept of limited variability regarding the application of accounting methods, which was implemented in practice in the USA by creating a system of GAAP US standards.

The freedom to choose accounting methods for researchers-accountants from English-speaking countries actually reduces to the question of the need for accounting regulation through its standardization.

Apart from the fact that accounting standards restrict the freedom to choose accounting methods and ensure better comparability of reporting indicators, which has become very relevant in the context of globalization of economic systems and relations, there are other reasons for their application, which in general justify the need for accounting regulation. One of the main reasons for the application of accounting standards is the cost savings for the development of individual accounting rules for each enterprise. This reason justifies the expediency of using accounting standards even for those enterprises that are not participants in international capital markets.

\section{Practical implementation of accounting standardization}

Despite the worldwide standardization of accounting under the slogan of international harmonization of accounting systems, some researchers oppose the regulation of accounting by standardizing it (Hendriksen E.S., \& M.F. van Breda, 2000; Sunder Sh., 2005; Watts R., 2008). The existence of such views confirms the thesis that the practical implementation of accounting standardization generates a significant number of problems related to the process of developing the standards themselves, the imperfection of their theoretical basis, the obsolete methodology used in scientific research, the effectiveness of their implementation as a means of regulating the accounting system. In order to improve the overall efficiency of accounting standardization, these problems require the fastest solution. However, in the vast majority of cases, the above problems are not related to the reduced freedom to choose accounting methods, which was one of the main tasks, assigned to the relevant accounting standards development agencies in the USA.

Currently, the choice of accounting methods presented in the accounting standards, along with strictly prescribed univariable rules, is an integral part of modern national and international accounting systems (e.g., NAS, GAAP US, IAS/IFRS), whose structural model is presented in Figure 2.

The presented model (see Figure 2) shows that the accounting system, in particular, in the part of its methodological apparatus, acts as a means of transforming the data on the effects of business operation items on the accounting information, which is the basis for making management decisions by users. A part of transformation means are fixed in the standards (imperatives), and other means of transformation

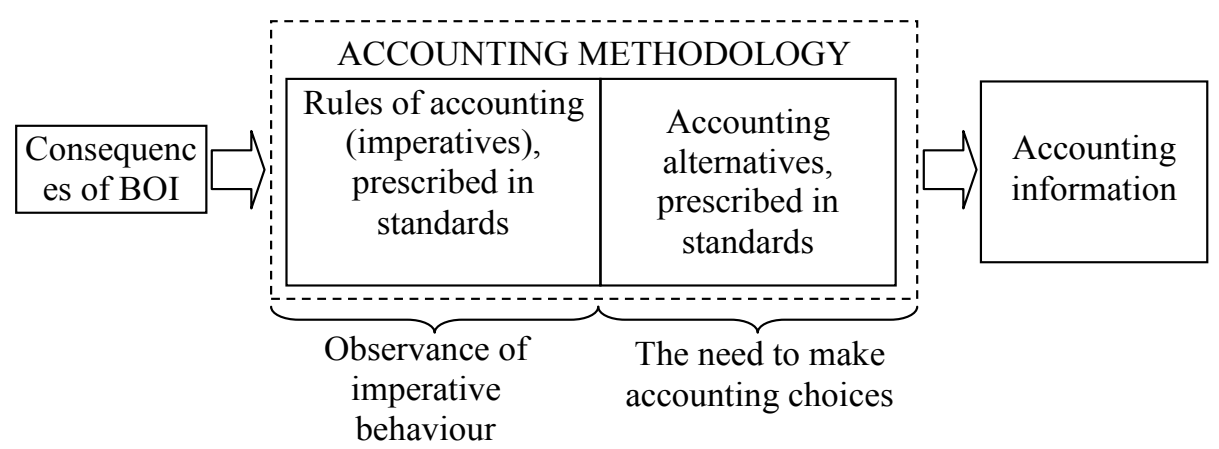

Figure 2. The structural model of the accounting system based on the concept of limited variability 
(alternatives) are chosen by the subject of accounting under the mechanism established in the higher that standards accounting documents (laws, conceptual foundations, etc.).

It should be considered that the movement towards such a model of the accounting system in the developed capitalist and post-Soviet countries took place in different ways, which can be represented as follows (Figure 3).

The transition to the concept of limited multivariability in the post-Soviet countries was carried out with the implementation of accounting harmonization with the requirements of IFRS through the introduction of national standards. In most post-Soviet countries, these processes began in the second half of the 1990s and continue to this day.

In the developed capitalist countries, the transition to the concept of limited multivariability began somewhat earlier - in the 70s and 80s of the XX century, along with the process of developing national and international accountingstandards(forexample, theUnited Kingdom1971, the USA - 1974, the IFRS - 1975, Australia 1984 , etc.) and the development of conceptual foundations to standards that revealed the limitations that should have been taken into account when making accounting choices.

Taking into account the fact that capitalist and post-Soviet countries have come to the use of the concept of limited multivariability in the accounting system (see Fig. 3) in other ways, one can explain some misunderstandings that arise among scholarsaccountants during scholarly disputes and discussions about accounting standardization issues. In particular, the fact that improving the quality of accounting information can be achieved by expanding the number of options for accounting display in the documents that govern the accounting process.

So, according to Prof. Ya.V. Sokolov and M.L. Piatov, refusal from excessive imperative statutory regulation of the accounting system makes it possible to expand the limits of the truthfulness of financial reporting (asit smooths the issue offinancial statements' compliance with the regulatory requirements for its formation) and, accordingly, to increase its realism (since it creates conditions for ensuring compliance with the actual state of affairs in the organization) (Sokolov \& Piatov, 2007).
In addition, the distinction found in the development of post-Soviet and capitalist accounting systems makes it possible to explain the views incomprehensible for some scholars of the Soviet school, in particular, similar to the thesis of S.A. Nikolaieva that professional judgment of the accountant in terms of developed market relations is a means of ensuring the reliability of information (Nikolaieva, 2000) that coincides with the general thesis about the need for accounting standardization. From the standpoint of Anglo-American scholars, accounting standardization ensures a better comparability of financial reporting indicators, as capitalist countries have switched to the concept of limited multivariability from the concept of partially unlimited multivariability. In this case, when disclosing arguments in favour of standards, their advantages are given in relation to the situation when there are no rules for the regulation of accounting. However, in this case, the advantages of accounting standardization are not considered in comparison with their complete monotonous regulation, when accounting is fully unified.

At the same time, this thesis is unacceptable for representatives of the Soviet accounting school, as they compare the concept of limited multivariability to the concept of extended univariability, which was used in the Soviet accounting system. The Soviet system of accounting, in turn, was focused on ensuring maximum approximation to univariable accounting methodology in order to implement a planned approach to economic management. Therefore, from the point of view of the representatives of the Soviet school, the standardization of the accounting system and the ability to make accounting choices based on the alternatives presented in the standards does not improve but worsens the comparability of financial reporting indicators and does not ensure the reliability of accounting information.

\section{The hierarchical structure of accounting methodology}

Figure 4 presents the hierarchical structure of accounting methodology in terms of reducing the number of alternatives to accounting.

Each of the highlighted zones (Zone 1 and Zone 2) includes all possible options for an accounting of zones of the lower levels. R. Watts and J. Zimmermann call

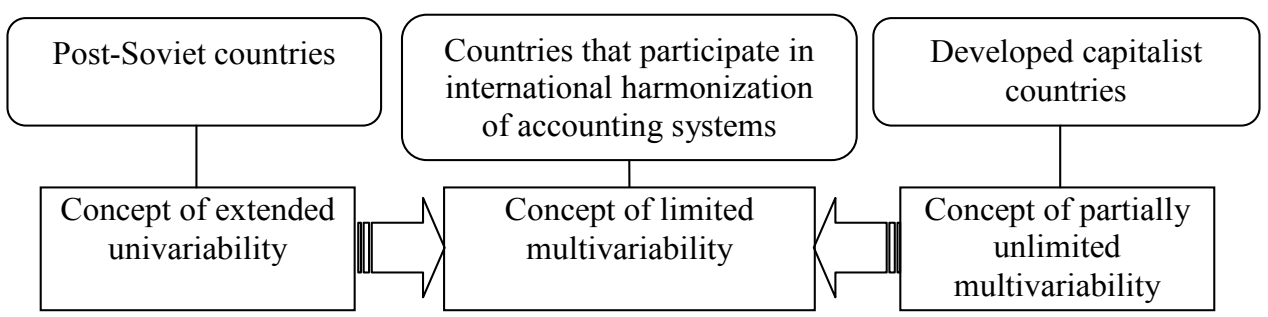

Figure 3. Accounting system development in capitalist and post-Soviet countries 


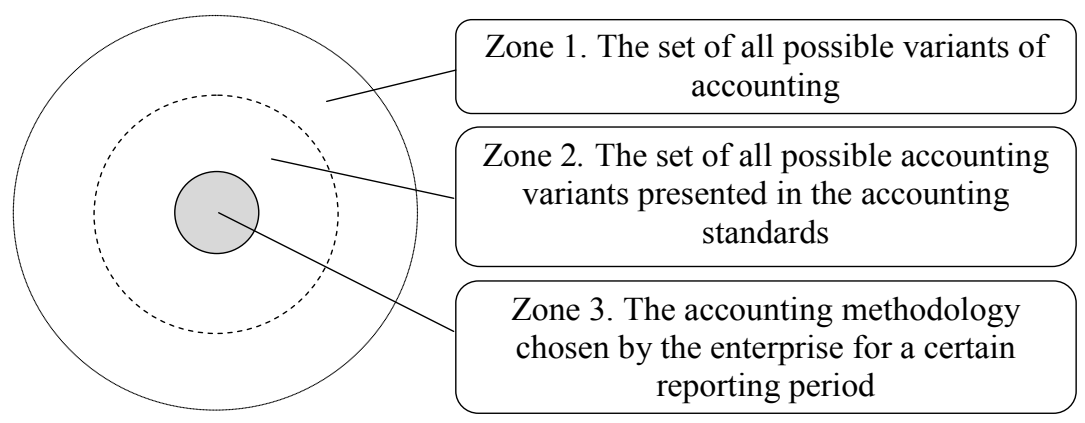

Figure 4. The hierarchical structure of accounting methodology

Zone 2 "permissible set", that is, a set of accounting procedures, when choosing from which managers have the freedom to act (Watts R.L., 1990). Proceeding from the theory of agency relations, this set of procedures (methods) is voluntarily determined by contract parties. Considering Zone 2 from the position of the NAS structure, it can be established that its boundaries are determined by the national regulator of the accounting system of the country, in which the enterprise or the international regulator (IASB) operates.

It should be noted that there is a different degree of influence of zones on each other. The emergence of new accounting variants in Zone 1 may remain unobserved by regulators (such as R. Chambers's Continuously Contemporary Accounting (COCOA) or T. Limperg's Deprival Value), which, as a result, will never be included in the accounting standards. This is associated both with the lack of a global "chart of accounting information models," as well as to the monopoly of regulators for the inclusion of new accounting methods in the system of accounting standards, which in most countries is conducted under the close supervision of ideologues and developers of GAAP US and IAS/IFRS.

The emergence of new accounting variants in Zone 2 expands the space for variation in accounting methods at the enterprise. And the exclusion of existing accounting variants in Zone 2 (for example, LIFO) is a direct indication of the need to change the accounting methodology of the enterprise (Zone 1).

Taking into account the proposed hierarchical structure of accounting methodology, it is possible to present the following changes in the structure of accounting methodology at the enterprise in different reporting periods (Figure 5).

Such changes take place subject to changes in the order of the accounting policy of the enterprise in terms of accounting methods and the invariability of the set of alternatives in the national accounting standards. When changing the latter, the structure of accounting methodology involves making changes not only in Zone 3 but also in Zone 2 .

The presented hierarchical structure (Fig. 5) illustrates two basic provisions of the modern model of the accounting system, built on the basis of the concept of limited multivariability:

- the methodology chosen and consolidated in the accounting standards (Zone 2) is only a certain set of alternatives that are chosen by the regulator from all possible options (Zone 1) and among which the accountants or managers of the enterprise can choose; - the accounting methodology, which is chosen by the enterprise, is fixed by the order on the accounting policy (Zone 3 ), is only one of the possible variants of accounting, accepted at the enterprise.

\section{Conclusions}

In order to form theoretical aspects of the concept of the variability of the accounting methodology, its basic concepts - imperative behaviour and accounting choice are substantiated. The following types of variability in accounting are distinguished: complete univariability;
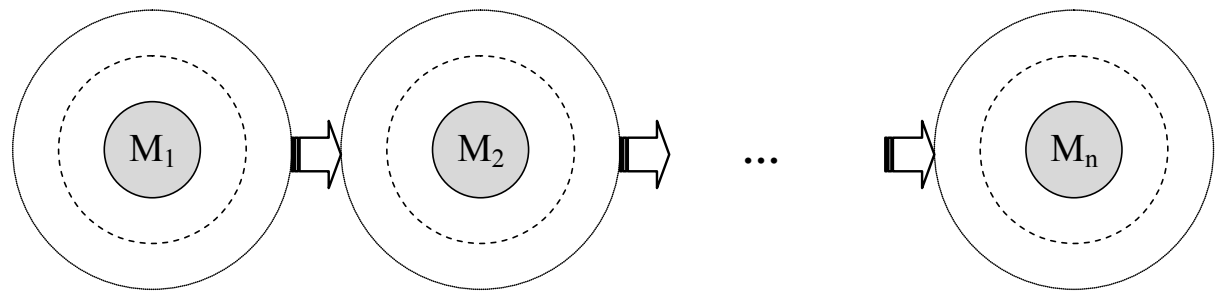

Note:

$M_{1}, M_{2} \ldots M_{n}$ - the methodology of enterprise accounting in the 1st, 2nd, and $n$-th reporting periods

Figure 5. Change in the structure of accounting methodology at the enterprise in different reporting periods 
extended univariability; limited multivariability; partially limited multivariability; full unlimited multivariability.

After analysing the basic provisions of the concept of accounting variability, we believe that further development of the NAS should be considered in the context of the following aspects:

1. At the enterprise level, there is the choice of accounting alternatives presented in the accounting standards of alternatives to accounting, which takes place under the influence of a significant number of objective and subjective factors. The existence of the ability to make accounting choices is associated with the use of a multivariable model as the basis of the NAS. In the light of this, one of the most relevant areas of accounting research is the theoretical justification of the place and role of accounting choice in the functioning of the accounting system, the search for analytical models that would allow users to take into account the possibility of influence of accounting choices on financial reporting indicators, the development of recommendations for improving the procedure for making accounting choices with the aim of eliminating abuses from the side of subjects of its implementation and increasing the relevance and fair presentation of financial statements. Of particular relevance this area of research is in terms of the hybrid war, when there is a gap between the owners of enterprises and their management, as a result of which the subjects of accounting organization can carry out opportunistic behaviour regarding the enterprise performance in order to achieve their own selfish interests that conflict with interests of owners.

2. The imperatives and alternatives to accounting presented in IFRS and in national $\mathrm{P}(\mathrm{S}) \mathrm{A}$ are not certain theoretical dogmas that cannot be changed or improved but are fixed in the standards by the accounting information models chosen by the regulator (the developer of accounting standards) from the set of the most common world accounting practices and at the present time meet the needs of users of accounting information. Further development of accounting methodology necessitates the improvement of accepted imperatives and alternatives (Zone 2 ) by excluding certain components from them (for example, as happened with the LIFO method) in case of changing the needs of users of accounting information, or vice versa - by expanding them, through the inclusion of new components from Zone 3. One of the present-day examples that confirms this thesis is the request made in early 2018 by the European Commission of High-Level Expert Group on Sustainable Finance to enable EU representatives to make changes to IFRS before they are introduced (GAAP.RU, 2018) because, in their present form, they do not always ensure that sustainability and objectives of long-term investments are taken into account.

\section{References:}

GAAP.RU. (2018). IFRS. The European Commission asks for permission to modify. Electronic resource. Retrieved from: https://gaap.ru/news/155419

Nikolaieva S.A. (2000). Professional judgment in the regulatory accounting system. 12, 50-55.

Sokolov Ya.V. \& Piatov M.L. (2007). A credible and conscientious view of accounting information. Accounting. 5, 52-56.

Hendriksen E.S. \& M.F. van Breda. (2000). Edited by Sokolov Ya.V. The theory of accounting. 576.

Solomons D. (1983). The political implications of accounting and accounting standard setting. David Solomons. Accounting and business research. 107-118.

Sottoriva C. (2013). Regards and views to accounting standards-setting. International Journal of Economics, Business and Finance. 4, 71-79.

Sunder Sh. (2005). Minding our manners: accounting as social norms. Yale International Center for Finance Working Paper. 05(18), 36.

Watts R. (2008). Accounting is exciting. MIT Sloan School of Management. 25.

Watts R.L. (1990). Positive accounting theory: a ten year perspective. The Accounting Review. 65(1), 131-156. 